\title{
A literatura funerária como fonte para a História Agrária do Egito Antigo
}

Ciro F. S. Cardoso

Universidade Federal Fluminense

\section{Introdução}

Em artigo ainda inédito, Bernadette Menu, partindo dos Textos das Pirâmides, traça um magnífico panorama do Reino Antigo, integrando os aspectos econômicos, sociais e ideológicos numa visão de conjunto. (1) Nosso objetivo, neste trabalho, é bem mais limitado. Partimos de indagações como as seguintes: será a literatura funerária fonte pertinente para o estudo da irrigação e das estruturas agrárias do Egito antigo? Que aspectos destes temas ela realmente ilumina? Até que ponto permite obter conhecimentos novos, em lugar de simplesmente corroborar outros documentos?

Ao pesquisar a história econômico-social do Egito faraônico, devido à relativa escassez de fontes específicas - em especial ao tratar-se dos períodos mais antigos - , o estudioso vê-se na contingência de, segundo a expresão francesa, faire feu de tout bois. Em outras palavras, torna-se necessário, com argúcia e um adequado manejo da crítica histórica e do confronto documental, extrair informações de tipo econômico-social também de biografias de funcionários, escritos religiosos, textos de ficção, etc.

Ora, as crenças funerárias egípcias, ligadas como estavam à construção e manutenção de uma tumba e a um complicado sistema de oferendas que deviam renovar-se regularmente segundo determinado calendário, tinham por força laços estreitos com a atividade agrária. $\mathrm{Na}$ economia baixamente mercantilizada do antigo Egito, a única maneira de garantir o mencionado sistema consistia em destinar a cada serviço funerário o rendimento

(1) - Menu, Bernadette, "Une approche de la notion de travail dans l'Ancien Empire égyptien", Florença, Instituto Gramsci, colóquio sobre Estado, economia e trabalho no Oriente Próximo antigo, outubro de 1984; esta comunicação será publicada nas atas do colóquio. 
de um ou mais estabelecimentos rurais, no todo ou em parte. Por outro lado, com detalhes cada vez mais abundantes conforme avançamos no tempo, os egípcios tenderam a imaginar a vida no outro mundo como um reflexo ou extensão das características do próprio país do Nilo. Por tais razões, as tumbas - sua iconografia, seus escritos - e os textos funerários fornecem inúmeras informações valiosas para a história agrária. $O$ texto mais explícito e detalhado sobre as formas de acesso à terra no Reino Antigo, a inscrição de Metjen, foi encontrado nas paredes de um sepulcro. Nas tumbas do mesmo período, além da iconografia explícita que ilustra os diversos aspectos da vida agrária, temos figurações alegóricas nas quais as unidades de exploração rural aparecem simbolicamente representadas por um desfile de mulheres - mais raramente homens - que carregam oferendas. Já no Reino Médio, os textos da tumba de Hapi-Djefai são extremamente preciosos para a compreensão das relações de propriedade e sucessão. (2) Poderíamos multiplicar os exemplos.

Este artigo pretende abordar um aspecto específico da questão: os Textos das Pirâmides, os Textos dos Sarcófagos e o Livro dos Mortos encarados como fontes para a história agrária do Egito faraônico. Nele apresentamos resultados parciais de uma pesquisa ainda não concluída.

\section{Textos das Pirâmides}

O corpo de escritos que assim designamos é conhecido através de inscrições achadas nas pirâmides do último rei da $\mathrm{V}$. $^{\mathrm{a}}$ dinastia, Unis, de diversos faraós da $\mathrm{V}^{\mathrm{a}}$ dinastia - Teti, Pepi I, Merenre e Pepi II -, das três rainhas de Pepi II, e na tumba do rei Ibi, que data provavelmente da VIII. ${ }^{a}$ dinastia. Se deixarmos de lado este último soberano, podemos dizer que os Textos das Pirâmides foram redigidos ao longo de dois séculos, aproximadamente entre 2356 e 2152 a.C. Constituem claramente, entretanto, uma fixação por escrito de elementos de épocas e tradições diferentes, alguns talvez de origem pré-histórica. Os "encantamentos" - como são chamadas as "falas" em que se dividem os textos, muitas de explícito caráter mágico, as quais deviam ser recitadas em voz alta - que os compõem foram inscritos, na sua maioria, em mais de uma pirâmide, mas poucos aparecem em todas. Os Textos das Pirâmides - que, portanto, não constituem um "livro" no sentido moderno do termo - são compilações

(2) - Menu, Bernadette e Harari, Ibram, "La notion de propriété privée dans l'Ancien Empire égyptien", Cahier de Recherches de l'Institut de Papyrologie et d'Egyptologie de Lille, 2, 1974, pp. 125-154: o artigo inclui o texto, com tradução e comentários, da inscrição de Metjen; Vandier, J., Manuel d'archéologie égyptienne, tomo IV, Primeira Parte, Bas-reliefs et peintures. Scènes de la vie quotidienne, Paris, A. et J. Picard, 1964, pp. 126-135, para os desfiles dos "domínios" rurais nas tumbas do Reino Antigo; Montet, Pierre, "Les tombeaux de Siout et de Deir Rifeh", Kêmi, 3, 1930-1935, pp. 45-111: contém as inscrições de Hapi-Djefai 
atribuídas aos sacerdotes do culto solar de Heliópolis, sem ordem lógica interna discernível, seja em cada tumba, seja no conjunto: trata-se de coletâneas para nós bastante disparatadas, destinadas a assegurar a sobrevivência e o destino glorioso dos reis mortos (3).

As contradições e incoerências que percebemos decorrem da associação de três tradições divergentes acerca da vida de além-túmulo: a concepção estelar, em que os mortos povoam o mundo das estrelas (Dat ou Duat), com ênfase particular concedida àquelas que, vistas do Egito, nunca se põem ao circularem no céu noturno (estrelas do norte, circumpolares); a concepção solar, que privilegia o Oriente do céu; e a concepção osiriana, que valoriza o Ocidente e um mundo dos mortos às vezes visto como subterrâneo. As duas primeiras visões são celestes e portanto mais facilmente conciliáveis: da concepção de um "céu superior" (Nut) e de um "céu inferior" (que se confundia de fato com as águas primordiais, ou Nun), passa-se a outra, baseada na complementaridade do céu diurno (solar) e do céu noturno (estelar); mas a concepção de um mundo subterrâneo dos mortos também já existe, embora ainda em caráter secundário, apesar de ser aparentemente irreconciliável com um destino celeste. Note-se que os Textos das Pirâmides só se interessam pela futura vida dos reis, mas supõem que as pessoas comuns tenham igualmente uma outra vida, já que elas neles aparecem, como astros ou como outros entes governados pelo deus solar e/ou pelo monarca ressuscitado.

A versão do destino final dos reis depois da morte que nos interessa mais neste artigo é a que se refere a uma espécie de paraíso agrário, constituído por regiões - celestes e/ou subterrâneas conforme as diferentes partes dos textos - aparentemente pantanosas, cercadas e cortadas por canais, chamadas Sekhet Iaru (Campo dos Juncos) e Sekhet Hetep (Campo das Oferendas): a primeira é situada mais firmemente no leste, enquanto a segunda parece ter oscilado entre leste e oeste (fixando-se definitivamente no oeste em textos da XI. ${ }^{a}$ dinastia) (4). Veremos, porém, que os Textos das Pirâmides são pobres em indicações específicas sobre a vida agrícola nesses "Campos Elíseos" egípcios, ao contrário dos Textos dos Sarcófagos posteriores (5).

(3) - Usamos as edições seguintes: Sethe, Kurt, Die altaegyptischen Pyramidentexte, 2 vols., Leipzig, J. C. Hinrichs, 1908-1910, para o texto original; e três traduções: Faulkner, R. O., The Ancient Egyptian Pyramid Texts, Oxford, Clarendon Press, 1969; Mercer, Samuel A. B., The Pyramid Texts in Translation and Commentary, vol. I, Translation, Nova Iorque, Longmans, Green \& Co., 1952; Speleers, Louis, Traduction, index et vocabulaire des Textes des Pyramides égyptiennes, Bruges, Imprimerie Sainte-Catherine, 1936. A tradução de Faulkner é em geral muito mais confiável.

(4) - Mercer, op. cit., vol. IV, Excursuses, pp. 1-6, 33-36, 65-68.

(5) - Sobre os Textos das Pirâmides, consultar: Breasted, James H., Development of Religion and Thought in Ancient Egypt, Filadélfia, University of Penn- 
A maior parte das informações de caráter agrário contidas nos Textos das Pirâmides decorre da busca de soluções para a alimentação do rei ressuscitado. Tais soluções são basicamente de quatro tipos: 1 . as oferendas terrestres, que através de diversos mecanismos divinos ou mágicos podiam chegar ao rei em sua vida de ultra-tumba; 2. o rei, uma vez instalado em alguma das versões do outro mundo, tinha aí acesso a alimentos e bebidas em modalidades variadas (sendo amamentado por uma deusa, colhendo cereais e frutos cuja proveniência exata ignoramos, recebendo nutrição por meios mágicos, ou recolhendo-a pessoalmente); 3. o monarca ressuscitado se punha a serviço de $\operatorname{Re}$ e passava então a usufruir das vitualhas dos domínios do deus solar, ou a ser alimentado por subordinados deste; 4. o rei recebia porções de terra ou delas se apoderava, e se dedicava pessoalmente à agricultura. São a primeira e a última das soluções as que abrem caminho a mais informações de interesse para a história agrária.

Em primeiro lugar, então, temos as oferendas feitas pelos vivos: em especial pelo faraó, sucessor do rei morto e pelo menos teoricamente seu filho, reproduzindo-se então a relação entre Hórus e Osíris.

Terras eram destinadas especialmente à produção de cevada (para a cerveja) e de emmer ou espelta (para o pão), de modo a prover "eternamente" de oferendas básicas o rei defunto (§§ 2069-2070 a). Além de pão - de vários tipos - e cerveja, diariamente eram-lhe oferecidos: figos, frutas diversas, carne bovina, aves, vinho, etc. Em ocasiões especiais, duas vezes por mês, as provisões apresentadas eram talvez mais abundantes e variadas, incluindo caça, objetos de alabastro, roupas, ungüentos, etc. (p. ex.: $\S \S 655-657, \S \S 695-696$, §§ 745-746 a, §§ 1882 a.2-1 883).

Em muitas das "falas" ou "encantamentos", o rei vivo, agindo como Hórus em relação ao seu pai Osíris, dizia ter pessoalmente cultivado a terra para prover as oferendas ao rei morto, o que, é claro, não deve ser tomado literalmente, mas apenas como afirmação de suas responsabilidades para com o culto funerário dos seus antepassados (p. ex. $\S \S 760-761$, $\S 1748, \S \S 1879-1880, \S 1950$ ). Eventualmente, a intercessão de seres divinos ou semi-divinos era solicitada para que não faltassem as oferendas

sylvania Press, 1972 (1. ${ }^{\mathrm{a}}$ ed. em 1912), capítulos III-VI: estudo pioneiro de conjunto, ainda muito útil; Budge, E. A. Wallis, Osiris and the Egyptian Resurrection, vol. I, Nova Iorque, Dover Publications, 1973 (1. ${ }^{\mathrm{a}}$ ed.: 1911), pp. 100-166: tem a vantagem de seguir de perto os textos, em ordem cronológica; Vandier, Jacques, La religion égyptienne, Paris, Presses Universitaires de France, 1949, 2." ed. (1." ed. em 1944), pp. 71-82: excelente síntese que integra as interpretações de Breasted, Kees e Sethe; Clark, R. T. Rundle, Myth and Symbol in Ancient Egypt, Londres, Thames \& Hudson, 1978 (1. ed. em 1959), capítulos I e III: comentários penetrantes; David, A. Rosalie, The Ancient Egyptians, Londres, Routledge \& Kegan Paul, 1982, pp. 72-75; Spencer, A. J., Death in Ancient Egypt, Harmondsworth, Penguin Books, 1982, pp. 139-142: os dois últimos livros são sínteses atualizadas. 
(p. ex.: § 1482). Ao mesmo tempo, fórmulas mágicas, pronunciadas ao apresentar tais oferendas, afirmavam que o rei morto tinha acesso garantido à água (às vezes identificada com a cheia do Nilo, com as águas primordiais ou com o líquido saído do cadáver de Osíris - origem mítica da cheia do rio) e portanto nunca teria sede (p. ex.: § 774 a-b, § 1291 a, $\S 2031 \mathrm{a}-\mathrm{b}$ ). Algumas vezes, ameaças eram feitas a certos deuses ou seres do outro mundo para garantir que as oferendas chegassem ao destinatário: "se o rei tiver fome, o Duplo Leão terá fome; se o rei tiver sede, Nekhebet terá sede" ( $\S \S 695-696)$. Certos trechos se referem especificamente às oferendas feitas no momento da inumação, por vezes apresentada como um fenômeno cataclísmico, durante o qual o céu tremia e trovejava, a terra se fendia, e o rei morto aparecia, transfigurado, para receber as oferendas (p. ex. § 817 a, § 1120 c, § 1138 a, § 1394 a-c).

Os textos relativos às oferendas podem ser úteis de diversas maneiras: fazendo conhecer os tipos de vinho e a localização dos vinhedos do Delta (p. ex. $\S 93 \mathrm{~b}, \S 94 \mathrm{~b}, \S 106 \mathrm{~b}$ ); especificando os tipos de pão (p. ex. $\S \S 1882$ a. $2-1883, \S 2069$ ) ou de cerveja $(\S 106)$, e em geral as plantas cultivadas e os animais criados e caçados naquele período.

Um conjunto numeroso de passagens dos Textos das Pirâmides se ocupa com a instalação do rei morto em alguma das versões do mundo de além-túmulo. O soberano, ao renascer, recobrava o uso de suas funçōes vitais - tema que aparece agora pela primeira vez (Encantamento n..$^{\circ} 317$, $\S \S 508-510)$ mas terá maior desenvolvimento na literatura funerária posterior. Cercado pelos nobres da corte do deus solar ( $\$ 754$ ), também na nova vida destinava-se a ser um juiz e soberano entre os mortos (p. ex. $\S 338, \S 1678$ ), num mundo que, como o Egito, tinha cidades e aldeias, e no qual era preciso alimentar-se. O soberano redivivo, ele mesmo um agente de fertilidade que fazia reverdecer a erva no horizonte celeste equiparado às margens de um canal (Encantamento n..$^{\circ} 317$, §§ 508-510), tinha acesso aos alimentos de diversas maneiras.

Ele aparece sendo conduzido - sob a forma de seu $k a$ ou duplo para o céu por Hórus, que o instala entre os "nobres do deus", que "vivem de figos, bebem vinho, são untados com ungüento" ( $\$ \S 815$ d-816), como também pode tornar-se a Estrela da Manhã no centro do Campo dos Juncos, gozando da abundância de que se alimentam os deuses, e ao mesmo tempo das oferendas terestres - quando não de árvores frutíferas que magicamente inclinam suas frondes diante dele (p. ex. § 805-808, §§ 1 018-1 019, $\S 1$ 395). E ainda recomendado aos apanhadores de pássaros, ou aos que controlam o acesso à comida e à água no Campo das Oferendas, ou ainda, por ter-se tornado um dos "veneráveis", aos que se ocupam dos festivais e das vitualhas de Osíris (p. ex. § 555, § 811, §§ 1 191-1 192, § 1 1991200 ). As soluções puramente mágicas também ocorrem: recitações, in vocações e saudações, seja ao Alimento, à Abundância, ao Grão, k Farinha 
de cereal, personalizados em entidades ( $\$ 1065)$, seja à Inundação celeste ( $\$ 1063 \mathrm{c}$, emendado por Sethe), seja ainda a plantas ( $\$ 689$ a) ou a personagens diversos. A simples afirmação, ao falar do rei, de que o rio em cheia "está em seu colo" e tâmaras "estão em seus punhos", pode garantir que assim aconteça ( $\S$ 699-701).

Num outro grupo de passagens, o rei morto transforma-se em escriba de Re: nesta capacidade, tem acesso aos celeiros do deus ( $\S 1182$ a-2) e é alimentado pelo mordomo, pelo açougueiro, ou por outros funcionários dos domínios da divindade solar (p. ex. §120, § 123 f, § 124, §§ $1059-1060$ a). Aí, porém, podemos aprender mais sobre a organização do abastecimento do palácio real - modelo em que é calcado o de $\mathrm{Re}$ - do que sobre temas agrários.

Também podia ocorrer, porém, que, para garantir o seu alimento, o soberano ressuscitado se transformasse em agricultor. Assim, ele aparece apoderando-se da parte meridional do Campo dos Juncos ( $\$ 1$ 084), no qual cultiva cevada e espelta (\$§ $873 \mathrm{c}-\mathrm{d}$ - 874). A deusa Tefenet divindade que personifica a umidade - ajuda-o escavando para ele um tanque no Campo dos Juncos e confirmando sua posse de terras no Campo das Oferendas (§ 289). Infelizmente, os Textos das Pirâmides não detalham tais atividades agrícolas.

A fonte é mais pródiga em dados sobre a cheia do Nilo e a irrigação. A concepção de que a produção agrícola constitui um "dom do Nilo" - a qual persistiria nos textos posteriores - é claramente afirmada ( $\$ \S 1553$ b-1 554, § 1557 a, \& 2 111). Por outro lado, o rei aparece irrigando, abrindo os regos que permitem que a água atinja os campos ( $\$ 857$ ), regando as terras que emergem dos tanques de irrigação ao baixarem as águas da cheia ( $\$ 388$ ). Em certos casos, a menção aos canais se liga tanto à inundação dos campos do outro mundo quanto à navegação ( $\S 343, \S 352$, $\S 359, \S 1084, \S 1102, \S 1205 \mathrm{~b}-\mathrm{d}$ ).

Por fim, merece menção um outro aspecto, de interpretação um tanto difícil: tem a ver com a herança e a partilha das terras. $O$ \& 475 afirma claramente: "Pobre é o herdeiro que não tem um documento". Efetivamente, sabemos que era prática corente, no Reino Antigo, a disposição da propriedade funerária por meio de textos escritos que estabeleciam os direitos e deveres das pessoas contempladas na sucessão (6). Menos claro é o sentido que se deve atribuir às pasagens que se referem aos territórios (ou aldeias) de Hórus e aos de Seth (p. ex. § 598 a-b, § 943 a-c, § 948 c, $\S \S 2$ 099-2 100). Baseando-se no confronto destas passagens com textos posteriores, que falam de "porções" atribuídas a Hórus e Seth pelos deuses reunidos em Conselho, ou pelo deus da terra Geb, J. Gwyn Griffiths lançou

(6) - Ver, em especial, o artigo de Menu e Harari citado na nota n. 2 supra. 
a hipótese de que refletiriam a lembrança do costume pré-histórico de que, nas aldeias neolíticas situadas ao longo do Nilo, a terra comunitária fosse atribuída em porções ks famílias pelos conselhos tribais (7). Embora esta hipótese não possa ser cabalmente verificada, é bom recordar que - como veremos - na literatura funerária posterior, é bastante freqüente a menção a conselhos análogos aos existentes nas aldeias e cidades do Egito (djadjat, knebet) relativamente a decisões ligadas à irrigação ou à confirmação da herança de Hórus.

\section{Textos dos Sarcófagos}

Se os Textos das Pirâmides e o Livro dos Mortos estavam publicados e eram já bem conhecidos e utilizados no início deste século, a publicação completa dos Textos dos Sarcófagos foi obra de Adriaan de Buck, resultando em sete volumes que surgiram entre 1935 e 1961 . A única tradução completa disponível foi publicada entre 1973 e 1978 (8). E fácil entender, então, que esta literatura funerária, recolhida de textos pintados ou inscritos em sarcófagos do Primeiro Período Intermediário e sobretudo das dinastias XI e XII aproximadamente 2134-1783 a.C.), permaneça ainda hoje menos conhecida e analisada do que sua predecessora das pirâmides e sua sucessora dos rolos de papiro do Reino Novo e do primeior milênio a.C.

Antes do trabalho monumental empreendido por de Buck, só se podia contar com uma publicação parcial dos Textos dos Sarcófagos, devida a P. Lacau. Era usual que os egiptólogos se referissem a esses textos como se se tratasse do Livro dos Mortos em versão anterior à do Reino Novo. Foi James H. Breasted quem sugeriu chamá-los "Textos dos Sarcófagos" (Coffin Texts), mostrando conterem partes bem diferentes em seu conteúdo do Livro dos Mortos posterior, e seu maior parentesco com os Textos das Pirâmides do que ocorre em todos os escritos funerários do Reino Novo em diante (9). Compreendem materiais provenientes dos textos do III. ${ }^{\circ}$ milênio a.C., às vezes modificados, e outros muito divergentes.

Os Textos dos Sarcófagos resultaram da generalização da religião funerária antes reservada aos reis - pelo menos na forma que nos foi pre-

(7) - Griffiths, J. Gwyn, The Conflict of Horus and Seth, Liverpool, Liverpool University Press, 1960, sobretudo pp. 147-148.

(8) - Buck, Adriaan de, The Egyptian Coffin Texts, 7 volumes, Chicago, The University of Chicago Press 1935-1961; Faulkner, R. O., The Ancient Egyptian Coffin Texts, 3 volumes, Warminster, Aris \& Phillips, 1973, 1977 e 1978. Nossa análise se baseará na tradução de Faulkner, razão pela qual as citações que remetem aos Textos dos Sarcófagos se farão indicando-se os números dos Encantamentos, seguidos dos volumes e páginas pertinentes daquela publicação. No entanto, em certos pontos nos afastaremos de Faulkner, baseando-nos então no original publicado por A. de Buck.

(9) - Breasted, op. cit., p. 273, nota 1. 
servada através das inscrições das pirâmides da V.a e da VI. ${ }^{a}$ dinastias - e a um punhado de privilegiados aos quais os monarcas concedessem a autorização e os meios materiais necessários para o estabelecimento de uma tumba e do respectivo culto baseado em invocações e oferendas. Agora, qualquer pessoa que pudesse arcar com as despesas correspondentes, estaria em condições de garantir para si um destino póstumo similar ao dos faraós do Reino Antigo. Esta evolução, atribuída por vários autores aos resultados de um surto revolucionário (10), implicou porém num trabalho de adaptação de que resultaram textos não somente mais abudantes e diversificados - a obra de A. de Buck contém nada menos do que mil cento e oitenta e cinco encantamentos! - , como também inovadores.

Em especial, no que nos interessa, percebe-se um avanço decisivo da concepção osiriana, mesmo se ainda associada (não sem hesitações e contradições) à concepção solar. Em consequiência, a descrição do "paraíso agráric" se precisou e se fez mais detalhada, como veremos. A visão estelar da vida de ultra-tumba tornou-se, no entanto, bem menos importante ainda que a possibilidade de um destino celeste para os mortos não desaparecesse totalmente. A solução para vincular as crenças solares e osirianas foi contrária à que predominara nos Textos das Pirâmides. Breasted, numa fórmula feliz, disse que "nos Textos das Pirâmides Osíris fora elevado em direção ao céu, enquanto nos Textos dos Sarcófagos e no Livro dos Mortos Re é arrastado em direção à terra" (11). Esta intrusão do deus solar no mundo subterrâneo de Osíris permaneceu em toda a evolução posterior das crenças funerárias egípcias. Mencionemos, por fim, que os Encantamentos 1029 a 1185 formam um conjunto conhecido como "O livro dos dois caminhos", consistindo numa visão do além como um mundo misterioso e apavorante, no qual o morto deveria se orientar e, ao mesmo tempo, escapar, através do conhecimento dos textos mágicos apropriados, de inúmeros monstros e outros perigos, até chegar finalmente à entrada do paraíso osiriano, o "país de Ra-setjä" (expressão - com freqüência transcrita como "Rosetau" - que designava a necrópole de Mênfis e significa "boca das passagens"), que conduziria ao "Campo dos Juncos" e ao "Campo das Oferendas" já presentes nos Textos das Pirâmides. Em certos sarcófagos de fins da XI . $^{\mathrm{a}}$ dinastia encontramos, mesmo, mapas sumários do outro mudo para orientação dos mortos (12).

(10) - Cf. principalmente Moret, A., "L'accession de la plèbe égyptienne aux droits religieux et politiques sous le Moyen Empire", in Recueil d'études égyptologiques dédiées à la mémoire de J.-Fr. Champollion à l'occasion du centenaire de la lettre à $M$. Dacier, Paris, Honoré Champion, 1922, pp. 331-360.

(11) - Breasted, op. cit., pp. 276-277.

(12) - Para uma visão de conjunto acerca dos Textos dos Sarcófagos, ver Breasted, Idem, pp. 272-284; Vandier, op. cit., pp. 86-100; Clark, op. cit., capítulos II e IV. Deixamos de citar obras muito mais especializadas como as de Piankoff, Lesko, etc. 
Como o rei defunto nos Textos das Pirâmides, nos Textos dos Sarcófagos o morto, ao renascer, recuperava o uso de suas funções vitais: certos encantamentos the garantiam a possibilidade de comer, beber, fazer o amor, praticar a magia e não ser destruído no outro mundo, de ali "fazer tudo o que ele desejasse, como quando estava na terra" (p. ex. Encantamentos: 184 , I, p. 154; 464, II, p. 90; 712, II, p. 270).

Também como o faraó, o ressuscitado se tornaria, no além, alguém de grande importância. Como escriba do Campo das Oferendas em nome de Osíris, ali distribuiria lotes de terra e controlaria os auxiliares do deus (Encantamentos: 279, I, p. 210; 329, I, p. 254). Poderia beneficiar com parcelas seus próprios seguidores, para os quais planejaria obras de irrigação, por ordem de $\operatorname{Re}$ (Encantamento 720, II, p. 273). Mais geralmente, governaria cidades e aldeias, delegaria autoridade aos mais capazes ou aos seus próximos; conheceria os ricos, favoreceria os pobres, protegeria a todos, seria enobrecido pelos deuses e nobres do mundo subterrâneo, e adorado pelas pessoas comuns (Encantamentos: 334, I, pp. 257-258; 397, II, pp. 26-27; 467, II, p. 95; 468, II, p. 98; 557, II, p. 167).

Todavia, no outro mundo como neste, era preciso alimentar-se. Uma das soluçōes consistia em transformar magicamente o morto num deus da fertilidade e da vegetação - Osíris, Hetep (personificação do Campo das Oferendas), o deus do Nilo (Hapi) -; quando não no próprio cereal: a identificação com o grão que é enterrado e renasce, aliás, era também uma imagem favorável à ressurreição (Encantamentos: 101, I, p. 99; 269, I, p. 205; 318, I, p. 246; 330, I, pp. 254-255; 467, II, pp. 95-96; 468, II, p. 98).

Outras soluções - que surgem em encantamentos numerosos demais para que os possamos citar — são do mesmo tipo daquelas que já encontráramos nos Textos das Pirâmides: as oferendas dos vivos (garantidas por campos e rebanhos, que, neste mundo, permaneciam ao serviço do culto funerário): aquelas providenciadas pelo filho do morto, por altares dos templos em que o defunto tinha direito a uma parte das provisões, etc.; o acesso, por concessão de uma ou mais divindades, a alimentos de diversos tipos no Campo dos Juncos ou no Campo das Oferendas; pôr-se a serviço de Re ou de Osíris e assim fazer jus a vitualhas; o recurso à magia, etc. De fato, diversos encantamentos retomam, a respeito, com ou sem modificaçōes de peso, passagens dos textos funerários do Reino Antigo. Para a história da agricultura, certas listas de oferendas - bem mais completas e informativas ocasionalmente do que as dos Textos das Pirâmides - provêem dados preciosos acerca das plantas cultivadas, dos animais criados ou caçados, e dos subprodutos daquelas e destes (o melhor exemplo é o detalhadíssimo Encantamento 936, III, pp. 70-75). 
O paraíso de Osíris era imaginado como um mundo agrário bem parecido com o próprio Egito, embora apresentando proporções majestosas nas suas plantas cultivadas e nos próprios cultivadores:

"Eu conheço aquele Campo dos Juncos que pertence a Re, cuja muralha que o cerca é de ferro; a altura de sua cevada é de quatro cúbitos, (sendo) a espiga desta de um cúbito, a haste de três cúbitos; sua espelta é de sete cúbitos, (sendo) a espiga de dois cúbitos, a haste de cinco cúbitos..." (Encantamento 159, I, p. 138.)

Devemos, então imaginar pés de cevada de pouco mais de dois metros de altura, com espiga de meio metro; pés de espelta ou emmer medindo quase quatro metros, com espigas de um metro; e imponentes "habitantes do horizonte" com quase cinco metros de altura!

Neste paraíso agrário, o acesso à tera, certas atividades agrícolas, a irrigação e as questões relativas à sucessão ou herança, aparecem organizadas por Conselhos de anciãos (13) (em um caso identificados à Grande Enéada divina) como os que existiam nas cidades e povoados egípcios (Encantamentos: 337 , I, p. 272; 338, I, p. 272; 339, I, p. 274; 353, I, p. 285; 405, II, p. 56) (14). Esta informação é de grande importância, já que - como o outro mundo era calcado estreitamente no próprio Egito lança alguma luz sobre o tema das comunidades agrárias egípcias, muito mal documentado no que tange ao Reino Médio.

Como já ocorria com o rei nos Textos das Pirâmides, o morto ressuscitado obtinha um ou mais lotes de terra para sustentar-se praticando a agricultura. Nem sempre é fácil decidir quando os Textos dos Sarcófagos se referem a lotes situados no outro mundo - no Campo dos Juncos ou no Campo das Oferendas - ou àqueles que, no mundo dos vivos, estavam reservados à provisão do culto funerário (p. ex. Encantamentos: 25, I, p. 16 ; 75, I, p. 73; 111, I, p. 106; 136, I, p. 116; 203, I, p. 165; 404, II, p. 50; 405, II, p. 56; 629, II, p. 262; 1159, III, p. 183; 1161, III, p. 183; 1164, III, p. 184). Às vezes os textos mencionam, além das terras agrícolas, verdadeiras mansões com tanques, jardins e árvores. Merece atenção bem especial o Encantamento 571 (II, pp. 172-173), que consiste na descrição de uma grande propriedade rural aparentemente situada no Delta (na região de Sais), contendo uma mansão, várias aldeias, instalações de irrigação, campos cultivados, árvores, jardins, rebanhos, pescarias, caçadores de aves, barcos, instalações para fabricação de vinho, tudo sob

(13) - As traduções de Faulkner empregam os termos "Tribunais" e "Grandes", mas os textos originais se referem mais exatamente a "Conselhos" e "anciãos".

(14) - Cf. Wainwright, G. A., The Sky-Religion in Egypt, Westport (Connecticut), Greenwood Press, 1971 (1. ${ }^{\mathrm{a}}$ ed.: 1938), pp. 26-32, para diversas correlações religiosas dos atos de arar a terra ou trabalhá-la com a enxada. 
a admiinstração de um intendente e tesoureiro que era o deus Seker, e sob o policiamento do deus Seth. Trata-se de um texto de grande valor, por permitir comparações com os poucos domínios rurais do Reino Médio para os quais temos documentação direta, como o de Hekanakhte (15).

Obtida a terra, o morto ganhava sua subsistência arando e colhendo (Encantamentos: 189, I, p. 158; 228, I, p. 181; 464, II, p. 90; 466, II, pp. 93-94; 467, II, pp. 95-96; 468, II, pp. 98-99, e outros). Os Textos dos Sarcófagos oferecem ricas informações acerca das atividades agrícolas, em certas ocasiões descendo mesmo a detalhes ínfimos: procurando os deuses Min e Anúbis, o ressuscitado os acha em plena colheita, "com suas foices (apertadas) entre suas coxas" - como podemos supor que faziam os trabalhadores que colhiam, quando por alguma razão interrompiam sua labuta, por exemplo para beber água (Encantamento: 397, II, p. 26). É igualmente representado o beneficiamento dos cereais (Encantamentos: 660, II, p. 231; 686, II, p. 252). Encontramos mesmo uma referência a um ano de má colheita - coisa bem freqüente durante o Primeiro Período Intermediário e até o final da XI. ${ }^{\mathrm{a}}$ dinastia -, (16) atribuindo-se a penúria a não se ter cultivado uma extensão suficiente de terras (Encantamento 671, II, p. 241). O Encantamento 472 (II, p. 106), referindo-se ao trabalho de corvéia, dá muitos detalhes acerca dos instrumentos agrícolas e de diversas tarefas: registro das terras ribeirinhas, abertura de novos campos ao cultivo, vigilância de equipes de trabalhadores, transporte de areia de uma à outra margem do rio. Pensava-se que esta areia servisse, entre outras coisas, para levantar os diques de irrigação, mas outra hipótese é que poderia servir para, misturando-a ao barro compacto deixado pela inundação do Nilo ao se retirar, obter-se terra cultivável com a consistência adequada (17). Mencionemos, por fim, que o Encantamento 713 (II, p. 270) talvez se refira à fermentação de tâmaras para fabricação de uma espécie de vinho.

O morto, ao ressuscitar, queria sem dúvida ser capaz de arar e colher, - que fazia parte da retomada de suas funções vitais. O ideal, porém, seria não ter de trabalhar no outro mundo, nem na corvéia para os governantes do paraíso subterrâneo de Osíris, nem nos próprios lotes pertencentes ao ressuscitado (p. ex. Encantamentos: 210, I, p. 169; 432, II, p. 73; 433, II, p. 73; 850, III, p. 35). Como consegui-lo? Uma das soluções parece ter consistido em fazer trabalhar em seu benefício deuses e outros

(15) - Ver Menu, Bernadette, Recherches sur l'histoire juridique, économique et sociale de l'ancienne Egypte, Versalhes, Edição da Autora, 1982, pp. 74-100.

(16) - Butzer, Karl W., Early Hydraulic Civilization in Egypt, Chicago, The University of Chicago Press, 1976, pp. 28-29.

(17) - Schneider, Hans, Shabtis. An Introduction to the History of Ancient Egyptian Funerary Statuettes, 3 vols., Leiden, Rijksmtıseum van Oudheden 1977, vol. I, pp. 57-60. 
seres fantásticos do mundo de ultra-tumba, pelo menos durante algum tempo (Encantamentos: 203, I, pp. 164-165; 404, II, p. 50; 405, II, p. 56; 696, II, p. 261). No caso específico da corvéia - devida no outro mundo como no Egito - a solução por excelência, inaugurada no Reino Médio, foi a de preparar estatuetas (shabtis ou ushabtis) que magicamente se transformariam em réplicas do morto, prontas a substituí-lo (Encantamento 472, II, p. 106).

O melhor, mesmo, seria reconstituir, na outra vida, a estrutura da "casa" de um egípcio importante, com seus pais e irmãos, sua esposa, seus filhos, suas concubinas, companheiros, dependentes e servidores. Assim, um conjunto de encantamentos - que por vezes assumem a forma de decretos legais, ou mesmo de ameaças aos deuses - tinha a finalidade de garantir a reunião do morto com sua família e seus dependentes (Encantamentos: 131, I, pp. 113-114; 132, I, p. 114; 136, I, pp. 116-117; 137, I, p. 118; 146, I, 123). Concomitantemente, os seus inimigos, e aqueles que não respeitassem os limites de seus campos terrestres ou do além, seriam ou destruídos (o morto é representado derrubando a casa do inimigo, esmagando seus filhos sobreviventes e "seu cultivador que está no seu campo"), ou entregues à sua mercê como "trabalhadores dependentes por concessão administrativa" (Encantamentos: 75, I, p. 74; 149, I, p. 127) (18). Estas passagens sobre as "casas" de egípcios de certa importância, vistas como unidades familiares extensas mas também contendo agregados e trabalhadores, confirmam e enriquecem a informação em relação ao tema que está nos papiros do Reino Médio encontrados em Kahun (19). Para que o trabalho de seus dependentes revertesse totalmente em seu próprio benefício, o morto tratava de livrá-los dos recenseamentos que baseavam a formação de equipes, e das corvéias exigidas por deuses, espíritos e outros seres do mundo subterrâneo (Encantamentos: 131, I, pp. 113-114; 146, I, pp. 23-124). A importância destes últimos textos, bem como do encantamento relativo às shabtis, consiste em mostrar a possibilidade que existia no Egito de obter isenção das corvéias - mal documentada para o Reino Médio - , bem como a da substituição em tal trabalho forçado para o estado (20).

(18) - Neste ponto a tradução de Faulkner - "servos comprados" - é inadequada: a expressão egípcia (de Buck, op. cit., I, 402 e), udj djet, refere-se a servidores obtidos mediante uma ordem administrativa, um decreto concedendo algo a alguém. Este é um exemplo dos problemas filológicos e de interpretação que é preciso enfrentar para tirar desses textos toda a informação que podem fornecer acerca das relações de produção.

(19) - Cf. Griffith, F. L1., The Petrie Papyri: Hieratic Papyri from Kahun and Gurob, 2 vols., Londres, Bernard Quaritch, 1898, vol. I, pp. 19-27.

(20) - Cardoso, Ciro F.S., "A corvéia no contexto econômico-social do Egito faraônico", História em Cadernos (Rio de Janeiro, Universidade Federal do Rio de Janeiro), Vol. II, n. 1, janeiro-agosto de 1984, pp. 19-25. 
O ressuscitado era, pois, representado como um chefe de homens, que ele pagava - como no Egito da época - mediante a distribuição de rações (Encantamento 188, I, p. 157) (21). Curiosamente, no Encantamento 720 (II, pp. 272-273), vemos o morto tomar a palavra como um proprietário resmungão: afirma que os "grandes" dão do que possuem, mas os "pequenos" nunca ficam contentes com o que recebem; ele não está satisfeito com seus dependentes (ou auxiliares), pois não vê o que fizeram em seu benefício. Isto recorda imediatamente as cartas de outro grande proprietário resmungão, Hekanakhte, e nos faz perguntar se não se trataria de um estilo que era socialmente esperado de um homem importante ao dirigir-se a seus subordinados, mesmo quando fossem parentes seus, ou ao falar deles (22).

Refiramo-nos agora, para terminar, às passagens relativas à água e à irrigação, muito numerosas. Sua primeira finalidade era garantir que o ressuscitado não morresse de sede, obtendo pelo contrário "poder sobre a água" através de expedientes variados (p. ex. Encantamentos: 225, I, p. 177; 356, II, p. 1; 358, II, p. 2; 359, II, p. 3; 361, II, p. 4; 362, II, pp. $4-5$; 547 , II, p. $161 ; 687$, II, p. 252 ; 793, III, p. 2; 820 , III, p. 11 ; 866 , III, pp. 42-43; 879, III, p. 46). Referências copiosas são feitas à crença de que a cheia do Nilo seria causada pelo efluxo saído do cadáver putrescente de Osíris (p. ex. Encantamentos: 68, I, p. 65; 74, I, p. 69; 358, II, p. 2; 362, II, pp. 4-5; 467, II, pp. 95-96; 626, II, p. 209; 680, II, p. 245; 833, III, p. 22; 1076, III, p. 146: neste último caso, o Nilo é "cuspido" pelo deus, ao qual o morto se identifica). Como nos Textos das Pirâmides, a cheia do rio é vista como causa direta da prosperidade dos homens vivos e mortos e dos deuses (p. ex. Encantamentos: 319, I, pp. 247-248; 327, I, p. 253; 660, II, pp. 230-231; 680, II, p. 245; 696, II, pp. 261-262; 1130, III, p. 167). No Encantamento 318 (I, p. 246), o morto identifica-se com o deus do Nilo e declara que a cheia não falhará sendo este o maior receio dos agricultores e administradores egípcios. $\mathrm{O}$ Encantamento 317 (I, pp. 241-242) é importante, pois confirma para o Reino Médio algo conhecido para o Reino Novo através de diversos documentos. Ou seja, que os egípcios distinguiam dois tipos básicos de solo agrícola: a "terra alta", normalmente produtiva, mas que em anos de cheia insuficiente podia ficar a seco; e a "terra baixa", que nunca deixava de receber a inundação (23).

(21) - Ver Mueller, D., "Some remarks on wage rates in the Middle Kingdom", Journal of Near Eastern Studies, XXXIV, 1975, pp. 249-263; Menu, Recherches..., pp. 114-133.

(22) - James, T.G.H., The Hekanakhte Papers and Other Early Middle Kingdom Documents, Nova Iorque, The Metropolitan Museum of Art, 1962: ver os Documentos n. 1 e n. 2 de Hekanakhte.

23 - Cf. Kees, Hermann, Ancient Egypt. A Cultural Topography, traduzido do alemão, Chicago, The University of Chicago Press, 1977, pp. 53.54. 
Em muitas ocasiões, "tanques", "nascentes", "correntezas", são mencionados sem detalhes que permitam vinculá-los à irrigação (Encantamentos: 74 , I, p. $69 ; 190$, I, p. $158 ; 686$, II, p. $252 ; 820$, III, p. 11 , entre outros). Mas há também numerosos referências explícitas à irrigação, incluindo as primeiras cronologicamente a caracterizarem, sem ambigüidade, o sistema de irigação por tanques separados por diques de terra que eram "cortados" quando necessário, para comunicar os tanques entre si e com o rio, típico do Egito (Encantamentos: 317, I, p. 242; 318, I, p. 246) (24). É possível que o Encantamento 140 (I, p. 120) nos tenha preservado, juntamente com os $\S \S 848$ e 857 dos Textos das Pirâmides, o vocabulário egípcio relativo aos três tipos básicos de canais: meru (canais maiores), iteru ("correntezas": talvez ligassem os canais maiores com o sistema de distribuição da água e minut (valas que cercavam os campos, suprindo aos regos menores que iam até as sementeiras a água recebida dos iteru) (25).

\section{Livro dos Mortos}

Como no relativo à literatura funerária anterior, também no Livro dos Mortos não temos um livro no sentido exato da palavra. Trata-se de um repertório de encantamentos, em grande parte derivado do conjunto que chamamos de Textos dos Sarcófagos, mas muito menos extenso: consta de cento e noventa e dois encantamentos, embora muitos tenham variantes. Diferentes seleções do mencionado repertório eram escritas em rolos de papiros e depositadas nos sarcófagos com as múmias ou, mais tardiamente, em imagens ocas da divindade compósita Ptah-Seker-Osíris colocadas na tumba. Se a transferência dos textos destinados à orientação dos mortos das paredes das pirâmides para os sarcófagos permitira, no passado, uma extensão do número de usuários da religião funerária, no novo sistema esta última conheceu difusão ainda maior. Havia por certo rolos preparados cuidadosamente, sob encomenda, com ilustrações numerosas e de ótima qualidade; mas também versões feitas às pressas, em série, contendo muitos erros de cópia, e com lacunas deixadas nos lugares apropriados para posterior inserção dos nomes dos compradores (26).

(24) - Yoyotte, J., "Egypte pharaonique: société, économie et culture", in G. Mokhtar (ed.), Histoire de l'Afrique, II. Afrique ancienne, Paris, Jeune Afrique-StockUNESCO, 1980, p. 107 (refere-se a de Buck, op. cit., IV, 138 b-c).

(25) - Faulkner, The Ancient Egyptian Coffin Texts, cit., I, p. 120, nota 1 relativa ao Encantamento n.० 140.

(26) - As versões do Livro dos Mortos que consultamos foram: Budge, E. A. Wallis, The Book of the Dead, Nova Iorque, Dover Publications, 1967 (ed. original: 1895): contém o texto original egípcio segundo o Papiro de Ani, transliteração e tradução; Larraya, Juan A. G., El Libro de los Muertos, Barcelona, José Janés, 1953: tradução do Papiro de Ani; Allen, Thomas George, The Book of the Dead or Going forth by Day, Chicago, The University of Chicago Press, 1974: embora tenhamos ocasionalmente lançado mão das outras versões citadas para certas interpretações, 
O conjunto de textos que constitui o Livro dos Mortos já se havia formado sob a XVIII. ${ }^{a}$ dinastia. Sofreu mudanças de peso na época das XXI. ${ }^{a}$ e XXII. ${ }^{a}$ dinastias, e de novo sob a XXVI. ${ }^{a}$ dinastia. Por fim, no periodo ptolomaico tornou-se usual uma determinada seleção e uma ordem fixa dos materiais. Assim, a evolução do Livro dos Mortos deu-se ao longo de mais de mil anos, a partir de meados do segundo milênio a.C. Aproximadamente $60 \%$ de seus encantamentos derivam dos Textos dos Sarcófagos, com modificações às vezes consideráveis; mas são poucos os que se vinculam aos Textos das Pirâmides (apenas cerca de 2\%). Dos materiais que não têm antecessores do Reino Antigo ou do Reino Médio, alguns tomaram de empréstimo elementos de outros textos funerários e religiosos do Reino Novo ("Litania do Sol", "Livro das Portas", "Livro das Cavernas", etc.).

A comparação do Livro dos Mortos com os Textos dos Sarcófagos mostra uma evolução no sentido de um compromisso eclético que, sem eliminar todas as contradições, estabeleceu certo equilíbrio entre a tradição solar e a osiriana. Mostra também um formidável avanço da magia, necessária para conjurar os perigos de um além-túmulo imaginado como ainda mais terrível do que a visão que dele se tivera no passado. A maior novidade do Livro dos Mortos consiste no grande desenvolvimento da noção - em si antiga - de que os defuntos seriam julgados no outro mundo, depois de evitarem com sucesso ameaças diversas pelo caminho, e antes de seu estabelecimento perpétuo no paraíso osiriano do Campo dos Juncos e do Campo das Oferendas. Neste caso igualmente, a magia poderia garantir que atravessassem com sucesso o julgamento, por exemplo pela recitação correta das fórmulas que com impropriedade chamamos de "confissão negativa" (Encantamento 125) (27).

A semelhança da parte pacífica e agrária do mundo dos mortos com - Egito dos vivos tornou-se ainda mais estreita. Por tal razão, mesmo se em algumas passagens o caráter subterrâneo do outro mundo é claramente indicado, E. A. Wallis Budge está certo em considerá-lo mais paralelo ao país do Nilo do que situado por baixo deste. A similitude chegou ao ponto de serem imaginadas, no reino de Osíris, subdivisões correspondentes aos diferentes nomos ou províncias do Egito, cada uma habitada pelos mortos

baseamo-nos nesta última, a mais completa e confiável de que se dispõe atualmente, indicando os encantamentos segundo sua numeração e parágrafos, seguidos das páginas correspondentes.

(27) - Acerca do Livro dos Mortos e outros textos funerários do Reino Novo e do primeiro milênio a.C., ver: Breasted, op. cit., pp. 293-311; Vandier, op. cit., pp. 100-109, 134-137; Clark, R. T. Rundle, op. cit., capítulos IV e V; Spencer, J. A., op. cit., pp. 142-164; Montet, Pierre, "Les fruits défendus et la confession des péchés", in Les sagesses du Proche-Orient ancien. Colloque de Strasbourg, Paris, Presses Universitaires de France, 1963, pp. 53-62. 
que houvessem vivido no nomo respectivo (28). Sendo assim, deveríamos perguntar-nos se o número dos "mortos bemaventurados", ou seja, 4.400.000 segundo um encantamento da XVIII. ${ }^{a}$ dinastia (Encantamento 64 , § S 8, p. 57; 7ncantamento 64 variante, § S 8, p. 59), não corresponde talvez à cifra de população que os egípcios do início do Reino Novo atribuíam ao seu país (29).

Para terminar esta síntese prévia à análise do texto quanto ao tema que nos ocupa, mencionemos ainda que "Livro dos Mortos" é uma designação moderna, inventada no século XIX. Alguns dos rolos de papiro que se conservaram trazem o título egípcio dessa literatura funerária: peret $m$ heru, ou seja, "Sair durante o dia". Este título mostra que, apesar de tudo aquilo com que a imaginação povoou o viçoso paraíso de Osíris, a aspiração máxima dos egípcios consistia em, após a morte, poderem voltar a este mundo durante o dia, embora tendo de regressar ao outro ao cair a noite.

Depois da considerável riqueza informativa dos Textos dos Sarcófagos quanto à história agrária, o Livro dos Mortos decepciona, mesmo sendo bem mais informativo do que os Textos das Pirâmides. Un dos problemas consiste em sua estreita dependência da literatura funerária dos sarcófagos no relativo a muitos pontos de interesse para a temática da agricultura e da irrigação. Torna-se difícil, às vezes, decidir até que ponto foi a continuidade de estruturas econômico-sociais o fator que garantiu a persistência de elementos temáticos no texto ou, pelo contrário, simplesmente o caráter conservador das convicções religiosas e o respeito supersticioso às formulações escritas herdadas do passado. Mesmo assim, algumas das modificações são significativas, e há materiais novos que refletem, em certos casos, novidades efetivas no âmbito da economia e da sociedade egípcias.

Como nas coletâneas funerárias anteriores, é por intermédio da crença na necessidade que sentiria o ressuscitado de alimentar-se no outro mundo que surgem, nos textos, aspectos de interesse para a história agrária.

Uma vez reassumidas as funções vitais (Encantamento $110, \S \S \mathrm{P} 1 \mathrm{e}$ $\mathrm{S} 3$, p. 87), o morto redivivo teria acesso em primeiro lugar às oferendas terrestres. Como no passado, o filho do falecido - eventualmente substituído, na prática, por um sacerdote - apresenta-se como Hórus que alimenta seu pai Osíris com oferendas; em forma enfática e apenas alegórica, declara haver pessoalmente, para tal, trabalhado a terra, construído canais,

(28) - Budge, Osiris. ., II, pp. 155-156.

(29) - As estimativas de Butzer (op. cit., capítulo 7) quanto à população egípcia sob o Reino Novo são bem inferiores: mas não passam de cifras hipotéticas, embora resultem de método interessante. 
fabricado pão e cerveja (30). Neste ponto, certa confusão se estabelece, pois menciona tê-lo feito no Campo dos Juncos, o que permite imaginar relação semelhante entre o morto (um Osíris) e o deus Osíris propriamente dito (Encantamento $173 \mathrm{~b}, \S \S \mathrm{S} 2,3$ e 4, pp. 181-182). As propriedades terrestres destinadas ao abastecimento do culto funerário são mencionadas, bem como os rebanhos e as vitualhas provenientes de altares divinos; fala-se também do controle que o morto pretende exercer sobre o fluxo das oferendas que recebe e que, em parte, por sua vez destina aos deuses. Ao barqueiro do Campo dos Juncos se ordena que transmita ao ressuscitado as oferendas (Encantamentos: $52 \mathrm{~b}, \S \S \mathrm{S} 1$ e 2, p. 52; $53 \mathrm{~b}$, $\S S 2$, p. 52; 68, §§ S 3 e 5, p. 62; 69, § S 2, p. 63; 70, § S 1, p. 63; 72 , § S 3, p. 65; 106, §§ P 1 e 2, S 1 e 2, p. 85). Numa passagem curiosa e tardia, pois data do período ptolomaico, o morto, como um fará, recebe os tributos dos nomos do Egito e dos países estrangeiros (Encantamento Pleyte 169.2, § S 3, p. 220).

Além do que ofereçam os vivos, através de invocações aos deuses e outros seres bemaventurados o morto ressuscitado, agora membro da corte de Osíris, também terá acesso à alimentação proveniente do mundo de ultra-tumba. Num encantamento que procede em linha direta dos Textos das Pirâmides (o de número 178.c), ele se vê recomendado aos subordinados de Re para que o nutram (Encantamentos: 1 , § S 5, p. 6; 6.A, $\S$ S, p. 9; 18, §§ T 5 e 6, p. 54; 77, § S, p. 66; 178.c, § S, pp. 186-187). O mais impressionante, porém, é mesmo o avanço da confiança em meios puramente mágicos. Ter conhecido em vida os textos adequados, ou mesmo simplesmente dispor de cópia deles num rolo de papiro depositado na tumba, eis o que basta para não passar fome na outra vida! (Encantamentos: 1 , T 1, p. $6 ; 15 . \mathrm{i}, \S \mathrm{T}$, p. $16 ; 135$, § T, p. 110.)

Para o nosso tema, o material acerca das oferendas, apesar de abundante, é muito menos informativo do que nos Textos dos Sarcófagos, por ter sido resumido destes, perdendo em detalhe no tocante à especificação de plantas, animais, tipos de alimentos preparados, etc.

Quanto à descrição geral do paraíso solar e osiriano no que tange à riqueza agrícola, as passagens pertinentes reproduzem as dos sarcófagos, nada trazendo portanto de novo (Encantamentos: 109.a, § S 2, p. 86; 149.b, $\S \S S 1$ e 3 ,p. 142).

Como nas literaturas funerárias anteriores, o ressuscitado em principio tornar-se-ia um agricultor no Campo dos Juncos e/ou no Campo das Oferendas, recebendo lotes de terra - por vezes surpreendentemente pequenos (certas passagens mencionam, seja um lote de $27.350 \mathrm{~m}^{2}$, seja um

(30) - Cf. Goyon, Jean-Claude, Rituels funéraires de l'ancienne Egypte, Paris, Les Editions du Cerf, 1972, pp. 98, 165-176. 
dez vezes menor) - "entre os que preparam comida para Osíris" (Encantamentos: $97, \S \mathrm{S} 1$, p. $77 ; 99$, §§ T e T variante 1 , p. 81; 144.f, § S 2, p. 122; 164, § T 3, p. 161; 89.k, §§ S 4, 5, 6 e 7, pp.212-213; Pleyte 166, § S 3, p. 216).

Também em comum com as aspirações que já caracterizavam os Textos dos Sarcófagos, o egípcio gostaria de não ter de trabalhar nos domínios de Osíris. Algumas das soluções para obter tal vantagem são, igualmente, as mesmas: as shabtis ou ushabtis como substitutos para a corvéia (31), e o uso de deuses e outros seres fantásticos como mão-de-obra - embora neste último ponto surja, como algo novo, o emprego das "duas filhas do Rei do Baixo Egito" como guardiãs das propiedades do morto no outro mundo (Encantamentos: 5, § P 1, p. 8; 6, §§ P 1 e 2, S 1 e 2, p. 8; 99, §§ T e $\mathrm{T}$ variante 1, p. $81 ; 189 . \mathrm{k}$, §§ S $4,5,6$ e 7, pp. 212-213). Há também novidades mais importantes, porém. Umas delas é o desaparecimento do tema da reunião do morto com sua "casa" - família, amigos, dependentes servidores - com o sentido de prover-se no além de trabalhadores (32): agora os textos se referem unicamente à reunião com o pai e a mãe (Encantamentos: 52.b, § S 3, p. 52; 110.a.6, § S 2, p. 89; 189.b, § S 3, p 211). A outra novidade é a menção explícita à escravidão. Fala-se de um escravo estrangeiro no Encantamento 90, § P 4, p. 214 (trata-se de um texto da XVIII. a dinastia). Há também uma passagem mais extensa:

"Os escravos, do sexo masculino e feminino, pertencem a tua Majestade. (Mas para) Osíris N., todos estes foram seus escravos enquanto esteve na terra. Foi ele quem os trouxe como rebeldes à sua cidade. Deixem-no governá-los em seguida; que eles façam o trabalho em seu lugar." (Encantamento Pleyte 166, § S 4, p. 216: neste texto, que é da XXI.a dinastia, quem fala é o deus solar Re. A letra N. substitui o nome do morto que naturalmente era diferente em cada rolo de papiro.)

A documentação do Reino Novo e períodos posteriores de fato não nos oferece relações de "casas" de pessoas importantes como as que conhecemos para o Reino Médio. E sabemos que a escravidão, em particular a

(31) - E interessante recordar que, no início do primeiro milênio a.C., a concepção acerca das ushabtis evoluíra, passando as estatuetas a serem vistas como representando escravos do morto, em lugar de substitutos para a corvéia: Edwards, I.E.S., "Bill of sale for a set of ushabtis", Journal of Egyptian Archaeology, 57, 1971, pp. 120,124 .

(32) - Budge dá aqui a informação contrária, mas isto se deve a uma leitura errada de um trecho do Encantamento 68, § S 3 (p. 62 na edição de Allen): ele leu "homens e mulheres que trabalham" para o morto, em lugar da leitura correta, "homens e mulheres que agem contra" o morto. Ver Budge, E. A. Wallis, The Egyptian Heaven and Hell, La Salle (Illinois), Open Court, 1974 (1. ${ }^{\mathrm{a}}$ ed.: 1905), pp. $65-66$. 
de estrangeiros vindos como presa de guerra ou como tributo aumentou muito com a expansão imperial do Reino Novo (33). Assim, as mudanças constatáveis nestes pontos no Livro dos Mortos em relação aos Textos dos Sarcófagos respondem a transformações econômico-sociais efetivamente ocorridas no Egito.

Vimos ser a chamada "confissão negativa" igualmente uma novidade na literatura funerária, embora se derivasse de um noção antiga mas vaga acerca do julgamento dos defuntos no outro mundo, e refletisse textos sapienciais de diferentes períodos. Ela contém algumas informações pertinentes para a história agrária, pois se refere a aspectos éticos que deviam moldar o comportamento esperado de um grande proprietário ou de um funcionário de alto escalão no antigo Egito (34). O morto declara, entre muitas outras coisas, ter-se abstido de: maltratar pessoas; impor aos seus servidores tarefas mais pesadas do que as usuais; roubar rações de pão (devidas aos trabalhadores); violar os limites dos campos; expulsar o gado menor de seus pastos; roubar ou matar gado pertencente aos deuses (ou apoderar-se de qualquer propriedade divina); exceder em suas necessidades o permitido por sua propriedade; e participar de questões legais, a não ser em defesa dessa propriedade pessoal (Encantamentos: 125.a, § S 2, p. $97 ; 125 . b$, §§ S 8, 13, 15, 18, 36 e 41, pp. 98-99).

Por fim, como no caso dos textos anteriormente analisados, o Livro dos Mortos inclui abundantes referências à água, à cheia do Nilo e seus efeitos e à irrigação. Embora afirme em certas passagens que o deus solar criou a água e a inundação - como tudo mais -, é frequiente a noção de que a Osíris se devem a cheia do Nilo (efluxo saído de seu cadáver), o germinar das plantas, o verdor dos campos, em suma a prosperidade deste mundo e do outro. Como filho de Osíris, Hórus - que é também o faraó - exerce controle sobre os homens, as terras, o rio, sua cheia, as plantas e em especial os cereais, e é de sua munificência que a humanidade obtém a saciedade e os deuses suas oferendas (Encantamentos: 15.A.3, § S 2, p. 18; 162 variante, § S 2, p. 158; 185.A, §§ S 1, 2 e 4, pp. 203-204; Pleyte 168, § S 34, p. 219).

(33) - Bakir, Abd El-Mohsen, Slavery in Pharaonic Egypt, Cairo, Institut Français d'Archéologie Orientale, 1952, pp. 5-6, 31-32, 69-82, 97-102. Bernadette Menu (Recherches..., pp. 184-199) nega a existência da escravidão no Egito antes da conquista do país por Alexandre o Grande: para ela, o termo "escravo", em se tratando do Egito faraônico, deveria ser substituído por "servidor", "dependente", "doméstico", etc. Esta é uma questão ainda não totalmente solucionada, embora pessoalmente não tenhamos dúvidas acerca da existência de escravos, não sendo porém um gênero de escravidão semelhante ao que encontramos na Grécia e em Roma no apogeu da civilização clássica.

(34) - Epsztein, Léon, La justice sociale dans le Proche-Orient ancien et le peuple de la Bible, Paris, Les Editions du Cerf, 1983, p. 77. 
O morto deseja ter acesso à água para matar sua sede no além: diversos encantamentos destinam-se a garantir seu controle sobre a água e a cheia fluvial, para beber e para finalidades de irrigação e fertilização do solo (Encantamentos: 58 \& P 1, p. 54; 59, § P 1 pp. 55; 60, § S 1 e 2, p. $55 ; 61, \S \S \mathrm{P} 1$ variante, $S$, p. $55 ; 62$.a $\S \S \mathrm{P} 1, \mathrm{~S} 1$ e 2 , p. p. 55; 68, $\S \S S 3$ e 5, p. $62 ; 149$, §§ S 1 e 2, p. 146).

Como nos Textos dos Sarcófagos, um Conselho preside à cheia do Nilo no outro mundo situado em Kheraha, que corresponde ao Velho Cairo, (35) bem como são mencionados conselhos com outras atribuições agrícolas e no relativo à herança ou sucessão. Todo este material segue de perto a literatura funerária do Reino Médio sem grandes mudanças (Encantamen-

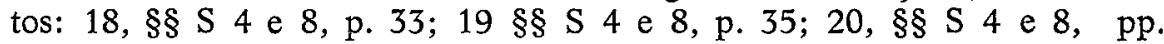
35-36; 57.a, § S 2, p. 54; 149.0 § S, p. 146).

A "confissão negativa" se refere também às instalações de irrigação. O morto declara não haver interrompido o fluxo da água "em suas estações" nem construído um dique para represar a água corrente; e não haver caminhado dentro d'água, o que a sujaria, além de talvez danificar as canalizações menores (Encantamentos: 125.a § S 2 p. 97; 125.b, § S 36, p. 99). O tipo de expectativa ética que implicam estas frases nos parece derivado de uma concepção do sistema de irrigação como obra coletiva e bem comum, não devendo seu bom funcionamento ser prejudicado por decisões ou interesses privados. Já nos Textos dos Sarcófagos, Atum-Re, o deus primordial declarava haver criado a cheia do Nilo "para que o pobre pudesse ser forte, tanto quanto o grande" (Encantamento 1130, III p. 167). Esta impressão se reforça se compararmos tais passagens de textos egípcios com as provisões claramente individualistas do chamado "Código de Hammurapi" acerca da irrigação, nas quais o legislador babilônico encarava diversos modos em que um proprietário privado de terras e canais pudesse prejudicar outros proprietários privados (36). Contudo, ao que parece, também no Egito a propriedade privada sobre as águas e instalações de irrigação terminou por se consolidar paralelamente à do estado: num documento do ano 5 do

(35) - Cf. Moret, Alexandre, Le Nil et la civilisation égyptienne, Paris, Albin Michel, 1937, p. 555: este Autor acreditava que os diversos conselhos locais do antigo Egito estavam subordinados ao "grande conselho da inundação" localizado em Kheraha.

(36) - Bouzon, E., O Código de Hammurabi, Petrópolis, Vozes, 1980 (3.a ed.), $\S \S 53$ a 56, pp. 42-43, §§ 259 e 260, pp. 101-102. E possível que a corvéia real fosse vista como tributo exigível pelo estado à população do Egito em troca do uso das instalações de irrigação: Hayes, W. C.: "Egypt: Internal affairs from Tuthmosis I to the death of Amenophis III", in I.E.S. Edwards et alii (eds.), History of the Middle East and the Aegean Region, c. 1800-1380 B.C., "The Cambridge Ancient History", vol. II, parte I, Cambridge, Cambridge University Press, 1980 (republicação da 3." ed., de 1973), p. 384. 
rei Sheshonk I (aprox. 940 a.C.), da XXII. dinastia há uma clara distinção entre as "águas do faraó" e as "águas de homens livres" (37)

\section{Conclusão}

Voltemos às indagações feitas ao começar, agora que estamos em condições de dar-lhes resposta A literatura funerária é fonte pertinente para o estudo da irrigação e das estruturas agrárias do antigo Egito, ilumina aspectos numerosos e variados destas temáticas, e em certos casos permite obter conhecimentos novos. É evidente, porém, que convém utilizá-la paralelamente ao resto da documentação disponível, e não em forma isolada: mas isto é verdade óbvia em relação a qualquer fonte histórica.

Neste artigo deve ter ficado claro, também, que o valor documental de cada uma das três grandes compilações de textos funerários é variável, em se tratando da história agrária. Os Textos dos Sarcófagos constituem o conjunto mais importante e rico em todos os sentidos, permitindo corroborações de peso e também a obtenção de conhecimentos novos importantes. Isto por serem o corpus funerário mais extenso e variado. $\mathrm{O}$ Livro dos Mortos é indubitavelmente mais resumido e às vezes muito dependente da literatura anterior dos sarcófagos, pelo qual contém muito de repetitivo para quem conheça esta última. Assim mesmo, em especial nas porçōes não derivadas dos Textos dos Sarcófagos, provê dados bastante relevantes, permitindo em certas ocasiōes apreciar mudanças estruturais ocorridas entre o Reino Médio e o Reino Novo. Em último lugar teríamos os Textos das Pirâmides, nos quais os aspectos agrários têm desenvolvimento bem menor. Mesmo neste caso, entretanto, é apreciável o que podemos obter, especialmente no tocante à irrigação - muito mal documentada através de textos escritos para o III..$^{\circ}$ milênio a.C. - , quanto às informações contidas nas referências às oferendas funerárias, e talvez também no relativo ao sistema de partilha das terras e de sucessão.

J. Vandier, na sua História da religião egípcia, se espanta de que os egípcios, que fizeram prova de tanta imaginação ao povoarem o caminho de acesso aos domínios de Oríris de monstros variadíssimos, lugares terríveis e contingências bizarras, tenham realizado somente na descrição do paraíso agrário osiriano uma transposição direta da vida terrestre no seu dia-a-dia tal como era conhecida no Egito. (38) E isto mesmo, porém, que transforma a literatura funerária em fonte confiável e às vezes tão rica para o historiador interessado nos aspectos econômico-sociais da civilização egipcia.

(37) - Gardiner, Alan H., "The Dakhleh stela", Journal of Egyptian Archaeology, 19, 1933, pp. 19-30.

(38) - Vandier, op. cit., p. 103. 